\title{
Construction of consistent ice core accumulation time series from large-scale meteorological data: development and description of a regression model for one North Greenland ice core
}

\author{
Traute Crüger ${ }^{1, *}$, Hans von Storch ${ }^{2}$ \\ ${ }^{1}$ Institute of Meteorology, University of Hamburg, Bundesstrasse 55, 20146 Hamburg, Germany \\ ${ }^{2}$ GKSS Research Centre, Max-Planck-Strasse, 21502 Geesthacht, Germany
}

\begin{abstract}
An empirical downscaling relationship is constructed which consistently estimates annual ice accumulation from large-scale meteorological data. The method by which the relationship was developed and the application of the method to one ice core are described. The statistical technique is based on a stepwise multiple linear regression using yearly accumulation as the predictand and the principle components (PCs) of seasonally averaged large-scale atmospheric fields as predictors. In order to separate the accumulation variations related to circulation and thermodynamics, the first step involves the stream-function field as the predictor. In the second step, temperature PCs are related to the residuals between real ice accumulation and accumulation described by stream-function PCs. One model is fitted for a North Greenland ice core. The atmospheric data are monthly NCEP Reanalysis data from 1948 to 1992. A statistical relationship is found which reproduces about $71.5 \%$ of local ice accumulation variability. The relationship involves 3 physically plausible streamfunction patterns, representing a seasonal mean (May to August) over Greenland, the North Atlantic and North Europe, which describes $64 \%$ of variance. In the second step, an additional contribution of the temperature field to the explained variance of $7.5 \%$ is achieved. The temperature PCs represent the annual mean $700 \mathrm{hPa}$ pattern covering the area from east Canada to east Greenland.
\end{abstract}

KEY WORDS: Ice core accumulation · Downscaling $\cdot$ NCEP-Reanalysis data

\section{INTRODUCTION}

In recent years many ice cores have been drilled and removed from the Greenland and Antarctic ice sheets. Climatic variables such as annual mean near-surface temperature and precipitation rates have been derived from these ice cores (Dahl-Jensen et al. 1993, Johnsen et al. 1995, Barlow et al. 1997, Jouzel et al. 1997).

One of the most important questions concerning icecore-derived data is to what extent they reflect atmospheric data. What climatic features do ice core data

*E-mail: crueger@dkrz.de represent? Much effort has been made to solve this problem. In particular, the question of whether there is a relationship between ice core data and the NAO (North Atlantic Oscillation) index has been investigated. White et al. (1996) used isotope data from the GISP2 core near the Summit of Greenland to investigate the representativeness of individual ice cores. They found that, at least for the last $100 \mathrm{yr}$, the ice core data follow regional climatic forcing: An NAO signal could be found. Appenzeller et al. (1998a,b) also related ice accumulation to the NAO index. They found strong correlations for west Greenland cores. However, they found that in the central and northern parts of Greenland the correlations between precipita- 
tion and the NAO index are not significant. Other atmospheric features have also been related to Greenland ice cores. White et al. (1997) found that for a stacked isotope record from Summit, as well as the winter NAO, solar irradiance, average Greenland coastal temperature, sea surface temperature at $30-20^{\circ} \mathrm{N}$ and the annual temperature seesaw between Jakobshaven/west Greenland and Oslo are related to the isotope record. Rogers et al. (1998) found that isotope ice core records from Summit are associated with sea-level pressure (SLP) and $500 \mathrm{hPa}$ height changes around Greenland, the North Atlantic and parts of Europe.

Only climate features of the past can be derived from real ice core data. Until now, it has not been possible to estimate future ice core data. If there is a relationship between atmospheric fields and ice core data, then 'artificial ice core' data could be estimated from general circulation model (GCM) output; these estimates would be subject to changes in the model parameters in the GCM runs.

In this paper we focus on the most important task in deriving artificial ice core data: i.e., to find a relationship between observed ice core data and those atmospheric features which are credibly simulated by GCMs. This condition cannot yet be fulfilled for local grid points. The minimum horizontal scale for which GCMs supply reliable results are a few grid points, representing a distance of about 2000 to $3000 \mathrm{~km}$ (von Storch et al. 1993). Furthermore, some model output parameters, for example, precipitation rates, are generally considered to be not credible. This is because precipitation is dependent on sub-grid-scale processes which are approximately parameterized. In particular, topography has an important influence on local and regional precipitation, which leads to unrealistic precipitation simulations if the GCMs have poor grid resolutions (von Storch et al. 1993, Leung \& Ghan 1998, Widmann \& Bretherton 2000). Because of the topographic features of Greenland, with elevations above $3000 \mathrm{~m}$, it is not reasonable to use this obvious predictor for our purpose. Moreover, validation of GCM precipitation against observations cannot be thoroughly examined because there are too few observations for Greenland (Stendel \& Arpe 1997). Thus the relationship used for the estimation of local ice core data must be based on more reliable GCM data, such as largescale velocity or temperature fields.

Here we show that it is possible to derive relationships which fulfill the criteria described above. For this purpose we use NCEP (National Centers for Environmental Prediction) Reanalysis data as predictors; these data are dynamically consistent estimates of the 3-dimensional atmospheric state. As the local predictand, the annual ice accumulation of one North Green- land ice core (B21 in central Northern Greenland) is chosen.

The statistical approach is based on the downscaling method described by von Storch et al. (1993). They related local precipitation at different sites on the Iberian Peninsula to large-scale SLP patterns. Here, the method is modified because only one local predictand is used. Since we want to take into account the influence of both temperature and circulation on ice accumulation, more than one atmospheric field is used as a predictor.

In the next section a brief summary of what is known about precipitation in North Greenland is given. Then the data for the development of the downscaling model and the downscaling method are described. Finally, the regression model for the North Greenland ice core accumulation time series is described and discussed.

\section{SEASONAL DISTRIBUTION OF ICE ACCUMULATION AND PRECIPITATION IN NORTH GREENLAND}

The ice core data used here represent annual accumulation rates. It can be assumed that ice accumulation in North Greenland is almost equivalent to precipitation, since sublimation can be neglected (Fischer 1997). Here, we provide a short description of precipitation in North Greenland, its seasonal distribution and the associated atmospheric features. Thus we can broadly assess whether annual or seasonal mean atmospheric fields can be used to estimate local ice accumulation.

Knowledge of the mean annual precipitation rates in the interior parts of Greenland is mainly based on ice core accumulation data, because continual measurements of precipitation have only been performed for some coastal regions during the last few decades. Ohmura \& Reeh (1991) produced an accumulation map for Greenland. They pointed out that an area with extremely low precipitation occurs on the northwestern slope of the ice sheet near the site of core B21 and suggested that topography plays an important role in the spatial distribution of accumulation in Greenland. Investigating the streamlines at $850 \mathrm{hPa}$ for January and July, they concluded that winter precipitation rates on the downward slope of the North Greenland ice sheet are low because the air coming from the south descends. In July, however, the northern part of Central Greenland is influenced by a low over the polar region and receives precipitation from the onshore flow at the west coast, which leads to a summer peak in precipitation. Chen et al. (1997) proposed an improved calculation of the vertical velocity in regions with high mountains. They developed a generalized $\omega$ 


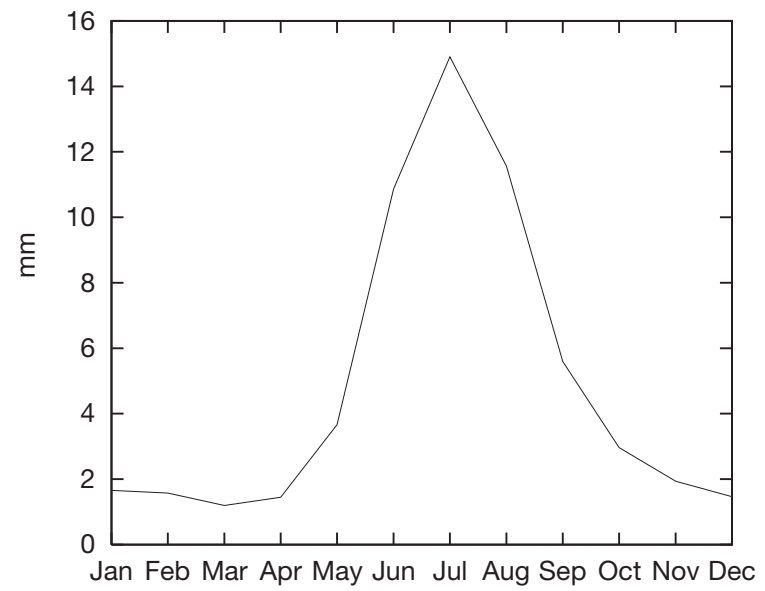

Fig. 1. Monthly mean NCEP reanalysis precipitation around core B21 (1948-1992)

equation without quasigeostrophic approximation in $\sigma$ coordinates which was used to reconstruct precipitation in Greenland for 1987 and 1988. For these years, they found that in the northern coastal region, where core B21 is located, precipitation mainly occurs in June/July. The associated atmospheric situation is characterized by lows over Baffin Bay and between North Greenland and Spitzbergen.

Serreze et al. (1993) investigated Arctic cyclonic and anticyclonic activity in summer and winter for the period between 1952 and 1989. They did not find noteworthy cyclones in winter which could influence the site of B21. In summer, a weak cyclonic area was found near the northwest coast of Greenland. Some of these cyclones move to the east. Thus they were able to account for ice accumulation in northeast Greenland. However, these cyclones are not very strong and do not occur very often, which corresponds with the small accumulation rates found for northeast Greenland (Ohmura \& Reeh 1991).

The seasonal distribution of North Greenland precipitation can also be investigated using NCEP Reanalysis precipitation data. Since the assimilation of observations into the NCEP model does not include precipitation rates, the NCEP precipitation data are short-range model forecasts (Kalnay et al. 1996). Thus they are subject to some errors. Stendel et al. (1997) investigated NCEP precipitation. They found unrealistic noise for the polar regions, which they related to the poor approximation of horizontal moisture diffusion in the boundary layer. For a few observation stations in the Arctic, they found an overestimation of precipitation in summer. Widmann \& Bretherton (2000) investigated NCEP precipitation in Oregon and Washington and found that for individual grid cells, systematic biases in NCEP precipitation exist, which are related to the poor resolution of topography. However, for spatial scales of about 3 grid cells, NCEP precipitation agrees well with the observations. Taking into account these uncertainties, we derived the monthly distribution of NCEP precipitation around the site of B21 averaged over 6 grid cells (Fig. 1). A pronounced maximum appears during the summer months June, July and August; during the rest of the year precipitation is negligible. This could be related to the overestimation of NCEP precipitation in summer found by Stendel et al. (1997), but also seems to confirm the results found by Chen et al. (1997) and Serreze et al. (1993), i.e., that the main precipitation in this region occurs in summer.

The findings described above indicate that the regression model for the annual ice accumulation at the site of B21 should mainly consider the summer months.

\section{DATA FOR THE DEVELOPMENT OF THE REGRESSION MODEL}

\subsection{Ice core accumulation}

The Alfred Wegener Institute for Polar and Marine Research (AWI) in Bremerhaven (Germany) performed a Greenland traverse between 1993 and 1995. They obtained and evaluated many ice and firn cores from the Central and North-Central Greenland ice sheet (Fischer 1997, Schwager 2000). In this paper, we only refer to the accumulation of the northernmost ice core, B21, located at $80^{\circ} \mathrm{N}, 41^{\circ} \mathrm{W}$ (Fig. 2) at an elevation of $2145 \mathrm{~m}$ above MSL. The core has been dated back to 1500. The mean accumulation rate during the overlap-

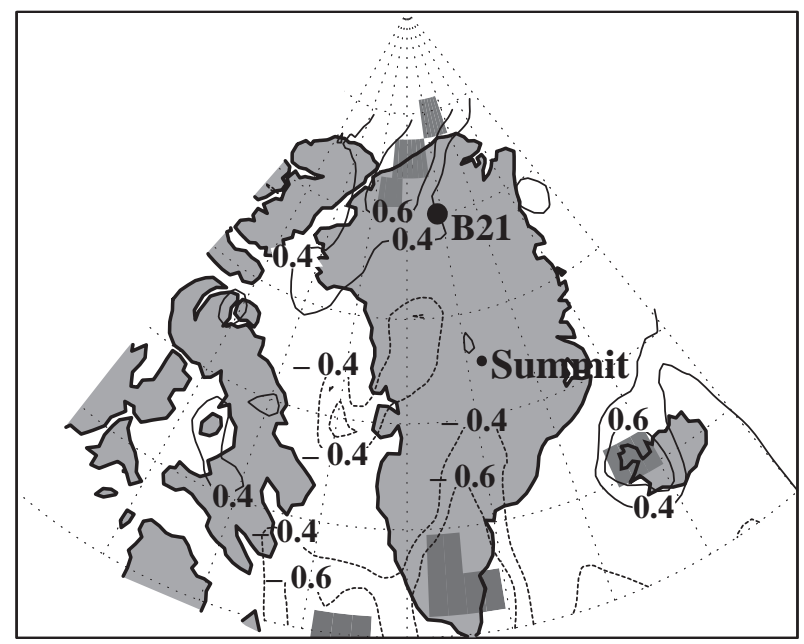

Fig. 2. Correlation between annual B21 ice accumulation and NCEP precipitation (1948-1992) (significant values are darkly shaded) 
ping period with the NCEP data (1948-1992) was

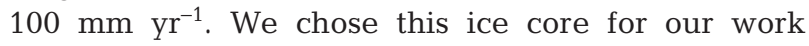
because it is considered that ice accumulation in northeast Greenland is mainly influenced by the mean atmospheric state, in contrast to central or coastal Greenland, where the ice cores are more influenced by single cyclonic events which are less likely to be described by the mean state, leading to more noise in the ice accumulation data (Fischer 1997).

As described above, it is possible to link some ice core time series to the NAO index. For core B21, however, the correlation between the annual NAO index (Jones et al. 1997) and annual accumulation is 0.11 for the period 1825-1993, which is not statistically significant (Schwager 2000). This agrees with the results obtained by Appenzeller et al. (1998a), who found that for the site B21, the correlation between monthly precipitation and an NAO index derived from ECMWF Reanalysis data is not significant.

The dating of the ice core is mainly based on the seasonal variation of the $\mathrm{SO}_{4}{ }^{2-}$ signal, which is caused by shifting of the polar front and results in a maximum of $\mathrm{SO}_{4}{ }^{2-}$ concentration in spring (Heidam 1984, Fischer et al. 1998a,b). The detection of these maxima is used to identify the accumulation of individual years (Fischer 1997). For the period considered here (1948-1992), a maximum dating error of less than $3 \mathrm{yr}$ is assumed (Fischer et al. 1998a,b). Additional uncertainties arise because the shifting of the polar front cannot be related to an exact date and changes from year to year. Therefore the period between $2 \mathrm{SO}_{4}{ }^{2-}$ maxima may not exactly represent $1 \mathrm{yr}$. However, in order to relate ice accumulation to atmospheric data, the date of the spring signal is set at May 1.

As well as the dating uncertainties, some errors arise from the ice core itself. They result, for example, from snow transport by wind or from horizontal distortion of the ice in lower layers. In order to reduce these uncertainties in annual ice accumulation rates, a weighted 5 yr running mean (with weights 1-2-3-2-1) was applied to the accumulation time series (see also Appenzeller 1998a,b). This is an appropriate method to reduce the errors, because accumulation rate errors partly cancel each other out when mean values are calculated, as accumulation cannot be lost.

\subsection{Atmospheric data}

The atmospheric data for fitting the regression model are monthly NCEP Reanalysis data from 1948-1992 (Kalney et al. 1996). The latitude/longitude grid for precipitation is about 1.9/1.9; for temperature and the horizontal velocity fields, it is $2.5 / 2.5$. As described above, well-simulated large-scale atmos- pheric fields are used as predictors for local ice accumulation. To decide which of the large-scale fields should be tested as predictors, it has to be kept in mind that the statistical model will eventually be applied to climate-change scenarios representing, for instance, the global warming phenomenon. The proportion of accumulation which can be described by circulation is derived using the $500 \mathrm{hPa}$ stream-function. We calculated this field from the horizontal velocity fields (Washington \& Parkinson 1986). In order to perform an exact calculation of the stream-function fields on a sphere, the wind components were interpolated onto a Gaussian T21 grid with mean grid distances of about $5.625 / 5.625$. In this way the grid is coarsened, which reduces small-scale noise, but does not influence the quality of the statistical relationships. For the application of the regression model, it is also advantageous that we do not need to interpolate the GCM data to a finer grid, since most GCMs have grids coarser than 2.5/2.5. To investigate how temperature change effects local ice accumulation, temperatures at 500 and $700 \mathrm{hPa}$ are tested as predictors. The $700 \mathrm{hPa}$ temperature is used because it roughly represents the highest elevation of the Greenland ice sheet (3200 m), and it is often assumed that the near-surface temperature is related to ice core accumulation (Dahl-Jensen et al. 1993).

In order to treat the atmospheric data in the same way as the ice accumulation time series, the fields were temporally smoothed with a weighted $5 \mathrm{yr}$ running mean after seasonal or annual gridded means were calculated.

\subsection{B21 ice accumulation and NCEP precipitation}

As mentioned above, B21 ice accumulation is assumed to be nearly identical to local precipitation. Furthermore, we mentioned that ice accumulation rates may be subject to error and that the local precipitation values of the NCEP Reanalysis may not be sufficiently reliable. However, if the temporal behavior of the precipitation and ice accumulation time series correspond well, it can be assumed that the ice accumulation time series are sufficiently reliable for our purpose. To examine this, a correlation map between B21 ice accumulation and NCEP precipitation is given in Fig. 2. The most striking feature of this map is that positive correlations are only obtained for northern Greenland, while for the south of the island the values are negative. This indicates an anti-correlation for precipitation over northern and southern Greenland, which may be related to ice sheet topography (Ohmura \& Reeh 1991). Ice accumulation at B21 is strongly related to precipitation on the northwest coast of 
Greenland, where the highest positive correlations (about 0.7) are found. This confirms the results of Serreze et al. (1993), who suggested that cyclonic activity on the northwest coast of Greenland affects the northern interior. The correlation at the core site itself is only about 0.4 . It is assumed that the reason for this behavior is the NCEP model orography or other local effects which are not of interest here. However, the most important result is that high correlation values of about 0.7 are found near B21. This supports the hypothesis that the ice accumulation data generally reflect precipitation variations and may therefore be downscaled from large-scale atmospheric states.

\section{DEVELOPMENT OF THE REGRESSION MODEL}

\subsection{Statistical concept}

The regression model should not only fulfill the criterion of high described variance of ice accumulation variability. It should also distinguish the accumulation variations related to circulation and thermodynamics. For this reason, a stream-function, representing circulation, and a temperature field, representing the thermodynamic impact on ice accumulation, are used as predictors. In the first step we only consider the stream-function. A regression model with the largescale stream-function field as predictor and ice accumulation as predictand is developed. In the second step, the residual of ice accumulation and accumulation estimated with the preliminary stream-function regression model is related to large-scale temperature. By performing this step-wise procedure, temperature, which is related to circulation, is not considered in the second step. In this way it is considered that the dynamic and thermodynamic influences on ice accumulation can be identified.

There are several ways to relate large-scale fields to local parameters. One possibility is to calculate correlation and regression coefficients between the predictand (here, local ice core accumulation) and all local predictors (here, large-scale stream-function) and then to plot correlation and regression maps. The advantage of this method is that it is easy to perform. It also provides a first estimate of the areas and seasons for which the atmospheric parameter is related to the local parameter. Unfortunately, the correlations are often small. Also, a cross-validation check indicates that the local regression coefficients are unreliably estimated. The reason for the failure of this approach is that it only partly uses the information of the predictor field, because it does not consider spatial dependencies.

A technique which does involve spatial dependencies is EOF (empirical orthogonal function) analysis (von Storch \& Zwiers 1999). Here, the anomalies $G^{\prime}(x, t)$ of a large-scale field $G(x, t)$ are expanded into a finite series as follows:

$$
G^{\prime}(x, t)=\sum_{i=1}^{m} g_{i}(x) a_{i}(t)+\varepsilon_{g}
$$

$g_{i}(x)$ are fixed patterns (called EOFs) and $a_{i}(t)$ are time coefficients, which are referred to as EOF coefficients or principle components (PCs). The residual $\varepsilon_{g}$ is considered to be noise and is neglected here. This method reduces the time dependencies to only a few time series which are related to fixed patterns containing information on the spatial distribution of the field. If fields can be found whose PCs have high correlations with the predictor field, it is likely that a regression model using the PCs as predictors will pass the validation tests. This approach is applied here.

EOFs and their PCs depend on the area boundaries and the average period of the field. In order to find a seasonal mean field whose PCs have the highest correlations with the annual ice accumulation series, we varied the boundaries of the field and the number of months whose mean is used for the EOF expansion. This way we also found the area and season of the predictor which is represented by local ice accumulation.

In order to build the regression model, when only the PCs of one predictor are considered, the regression coefficients can be obtained by the following simple formula:

$$
k_{i}=\frac{\sum_{t=1}^{n} a_{i}(t) A_{c}^{\prime}(t)}{\sum_{t=1}^{n}\left[a_{i}(t)\right]^{2}}
$$

since the PCs of one field are linearly independent and uncorrelated. Here, $k_{i}$ is the regression coefficient of the $i$ th $\mathrm{PC}$, and $A_{\mathrm{c}}^{\prime}(t), t=1, \ldots, n$, are the anomalies of the local ice accumulation time series. The estimated accumulation anomalies $A_{\text {esti }}^{\prime}(t)$ are obtained from:

$$
A_{\text {esti }}^{\prime}(t)=k_{l} a_{l}(t)+k_{m} a_{m}(t)
$$

When a second atmospheric field is considered, the procedure described above is repeated. However, now we search for high correlations between the predictor PCs and the residual $A R_{\mathrm{c}}^{\prime}(t)=A_{\mathrm{c}}^{\prime}(t)-A_{\text {esti }}^{\prime}(t)$, which is derived from the real ice accumulation and the accumulation estimated by the predictor PCs of the first step. Therefore, in Eq. (2), the predictand $A_{\mathrm{c}}^{\prime}(t)$ is replaced by $A R_{\mathrm{c}}^{\prime}(t)$. Regarding the second predictor, Eq. (3) is extended to:

$$
A_{e}^{\prime}(t)=k_{1} a_{1}(t)+\ldots+k_{m} a_{m}(t)+r_{m+1} b_{1}(t)+\ldots+r_{m+m} b_{m}(t)
$$

$A_{\mathrm{e}}^{\prime}(t)$ is the estimated accumulation after the second step, $b_{j}(t)$ the PCs and $r_{m+j}$ the regression coefficients of the second predictor field. For our purpose, we only 


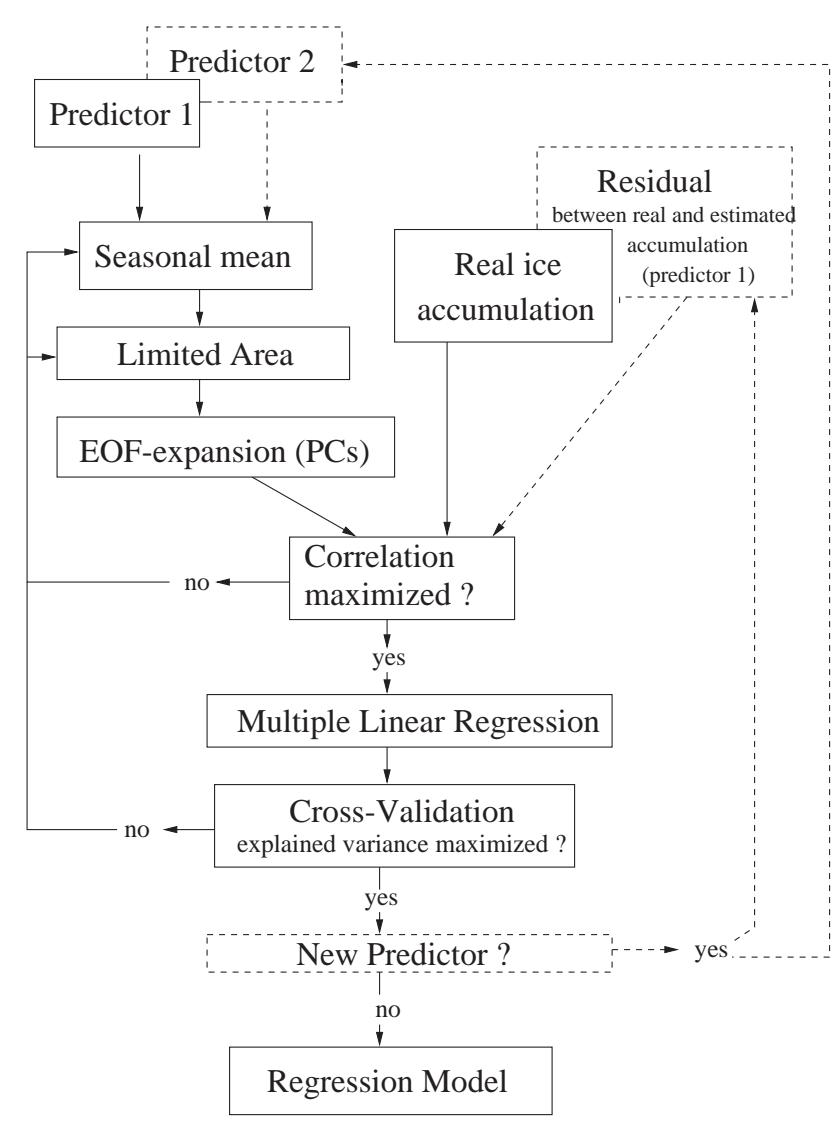

Fig. 3. Schematic of the general procedure for the development of the regression model

select a few PCs for the regression model, which have high correlations with $A^{\prime}{ }_{\mathrm{C}}(t)$ and $A R^{\prime}{ }_{\mathrm{C}}(t)$, respectively.

In Fig. 3, the construction of the statistical model which yields the highest described variance of local accumulation is summarized. The general procedure for estimating ice accumulation consistent with GCM output is shown in Fig. 4.

\subsection{Validation}

If all of the time series data were to be used for model development, a reconstruction of the ice core data using atmospheric data would be obtained, the skill of which would be overly optimistic. To determine the true skill of the model, it has to be applied to independent data. One possibility is to split the series into 2 parts: one part for the development of the statistical model, the other for validation. However, this is only practical when the split time series are long enough to yield a reliable statistical model. Our time series, which consist of only 45 data points, are too short for this kind of validation. The method used here is there- fore cross-validation, which has been developed for short time series (von Storch \& Zwiers 1999). In this method, a few time steps are removed from the entire time series. The data for the remaining time steps are used to develop a regression model (calculation of gridded average fields, gridded anomalies, EOFs, PCs and regression coefficients). Then, this model is applied to one of the removed and therefore independent time steps. Performing this procedure stepwise, all time steps can be used for validation. Since it has to be guaranteed that both the fitting and the validation data are independent, 9 time steps are removed from the time series. This is because the running mean procedure is performed over 5 time steps for the predictand and the predictor series. The 5th of the 9 time steps is the validation time step.

\section{REGRESSION MODEL FOR B21}

By performing the procedure described above, we found the season and area boundaries of the $500 \mathrm{hPa}$ stream-function, for which a maximum of variance of B21 accumulation is described. The field is averaged from May to August and ranges from the northeastern coast of Canada to northeast Europe and from $85^{\circ} \mathrm{N}$ in the north to southern England in the south (Figs. 5 to 7). Obviously the relationship between B21 ice accumulation and the atmospheric pattern over Asia, the Pacific and America is not important. The EOF PCs which are correlated with the B21 ice accumulation time series are the $1 \mathrm{st}$, the $3 \mathrm{rd}$ and the 4 th. The $1 \mathrm{st}$ EOF, whose PC has a correlation coefficient of $\mathrm{r}=0.65$, explains $73 \%$ of the variability of the stream-function field. The pattern is characterized by strong anticyclonic flow centered over the Skagerrak, accompanied by southern/southwestern winds over the North

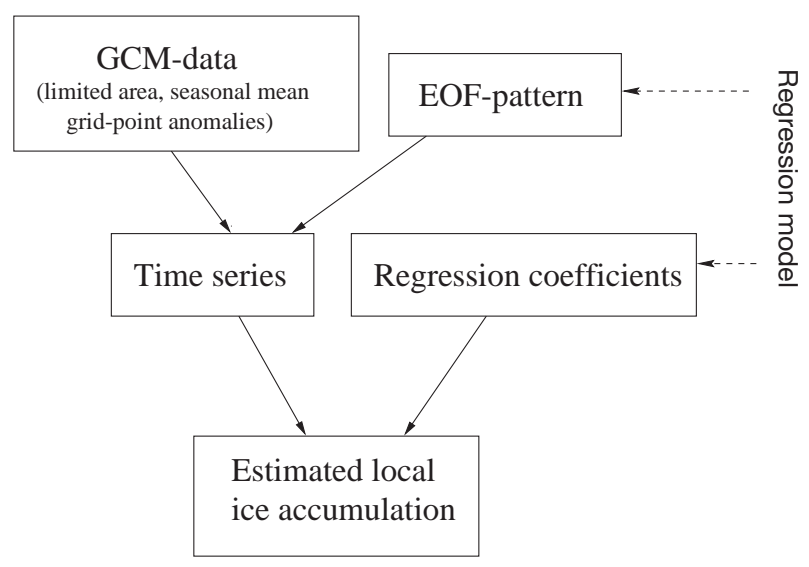

Fig. 4. Schematic for ice accumulation estimation using GCM output 


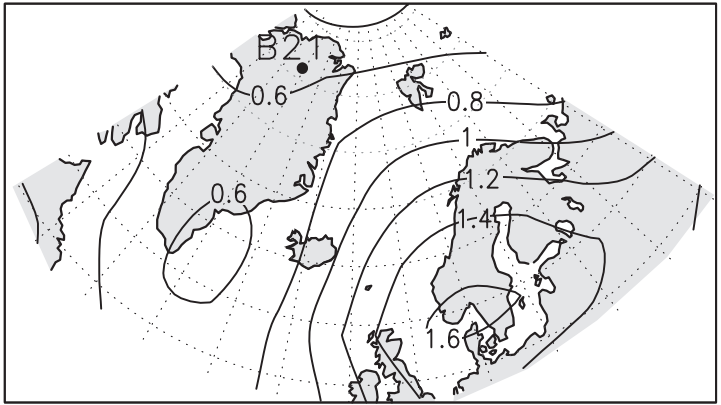

Fig. 5. First EOF pattern of the NCEP $500 \mathrm{hPa}$ stream-function (averaged from May to August) (1948-1992)

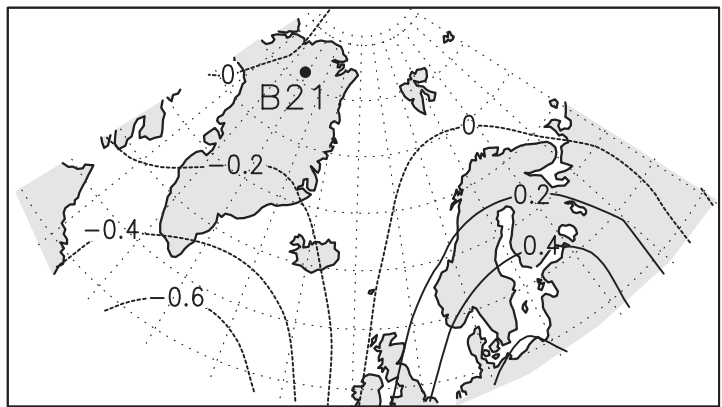

Fig. 6. Third EOF pattern of the NCEP $500 \mathrm{hPa}$ streamfunction (averaged from May to August) (1948-1992)

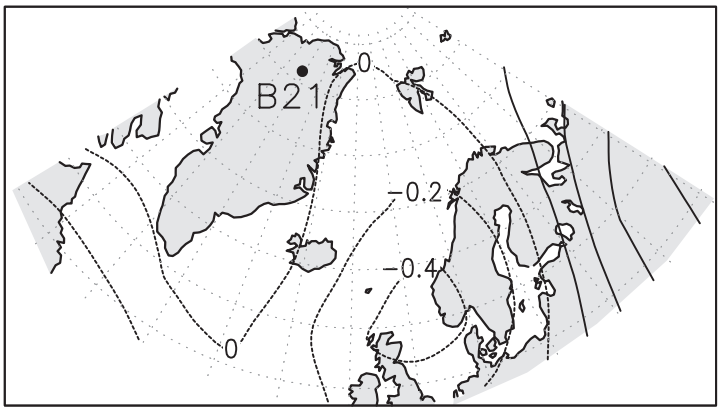

Fig. 7. Fourth EOF pattern of the NCEP $500 \mathrm{hPa}$ streamfunction (averaged from May to August) (1948-1992)

Atlantic (Fig. 5). Near the core site, mean westerly winds are found. At the southeastern coast there is weak cyclonic flow. The 3rd EOF represents $6 \%$ of the stream-function variability. The correlation between B21 ice accumulation and the 3rd PC is 0.4 . Over north Europe, the pattern has anticyclonic flow, while south of Greenland cyclonic flow is indicated (Fig. 6). Near the site of B21, weakly mean northeasterly flow is found. The correlation coefficient between the 4th PC (explained variance of stream-function: $4.5 \%$ ) and ice accumulation is 0.29 . The main feature of this pattern is cyclonic flow centered between Scotland and Norway, which leads to southerly winds in north Europe (Fig. 7). It also affects the northeast coast of Greenland with weak northern flow. No strong winds are found over Greenland.

About two-thirds of the variance of local ice accumulation can be explained by the summer-mean streamfunction field. Thus the additional contributions from other predictors must be much smaller. For other seasonal mean stream-function fields (for example, the winter mean), no additional contributions to the explained variance of B21 ice accumulation are found. The question arises of whether there is a contribution related to the temperature field. To investigate this, the residual of B21 ice accumulation and accumulation estimated from the stream-function model is used as the predictand (as described above). Both the 500 and $700 \mathrm{hPa}$ levels of temperature are investigated as predictors. The highest correlation is found for the $700 \mathrm{hPa}$ level. The 3rd PC of the annual mean field (which explains about $14 \%$ of the variability of the temperature field), spanning an area from the northeast coast of Canada to east Greenland (Fig. 8), has a correlation coefficient of 0.46 . The temperature pattern shows small negative anomalies for at least the northeastern part of Greenland, indicating that positive ice accumulation residuals are related to negative annual temperature anomalies. The 4 th EOF, whose PC has a correlation coefficient with the residuals of 0.39 , shows small positive temperature anomalies over nearly the entire Greenland area (Fig. 9). The correlations found for the temperature PCs are relatively small compared to those of the stream-function PCs. But one should keep in mind that, besides the physically related contributions to the explained variance, the residuals include the errors and noise of the accumulation time series.

Validation experiments were made with regression models developed performing (1) only the first step (only 3 stream-function PCs) and (2) the first and second steps (3 stream-function PCs and the additional 2 temperature PCs). As expected, the explained variances are somewhat smaller for the validated time series than for the reconstructed ones. The streamfunction model yields an explained variance of $64 \%$ and the model including stream-function and temperature effects $71.5 \%$, indicating that the additional contribution obtained from the annual temperature field is about $7.5 \%$ of explained variance. In Figs. 10 \& 11 the validated time series are shown. The general behavior of the observed ice accumulation variability is well reproduced by both models. For the full model (stream-function and $700 \mathrm{hPa}$ temperature PCs), better results are obtained for some details, such as the period with negative anomalies from 1955 until 1965 


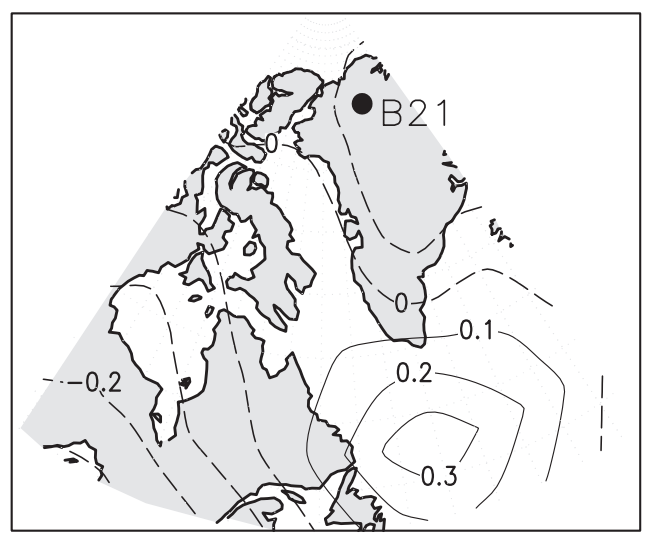

Fig. 8. Third EOF pattern of the annual mean NCEP temperature field $(700 \mathrm{hPa})$

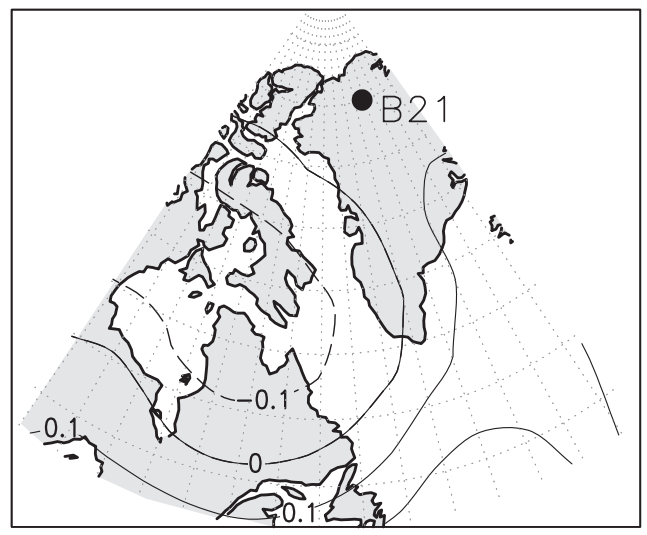

Fig. 9. Fourth EOF pattern of the annual mean NCEP temperature field $(700 \mathrm{hPa})$

and the improvement of the estimations for 1970-1972. The observed phase is mostly well reproduced. However, the minimum in 1976-77 is shifted to 1978 . The main differences between the estimated and the observed time series are found in the amplitudes, which are mostly smaller for the estimated values, as to be expected from any regression model.

The regression model described above indicates a small influence of temperature on ice accumulation at B21. This result is due to the method used to develop the regression model: that part of temperature which is linked to the stream-function is eliminated when the first predictor is the stream-function. If the temperature PCs are directly correlated with the ice accumulation time series, then a field is found which explains about $52 \%$ of local ice accumulation variance of B21 after validation. The first $\mathrm{PC}$ of the annual mean $700 \mathrm{hPa}$ temperature field (which explains about $73 \%$ of the temperature field variability), covering only Greenland, has a correlation coefficient of 0.74 . The

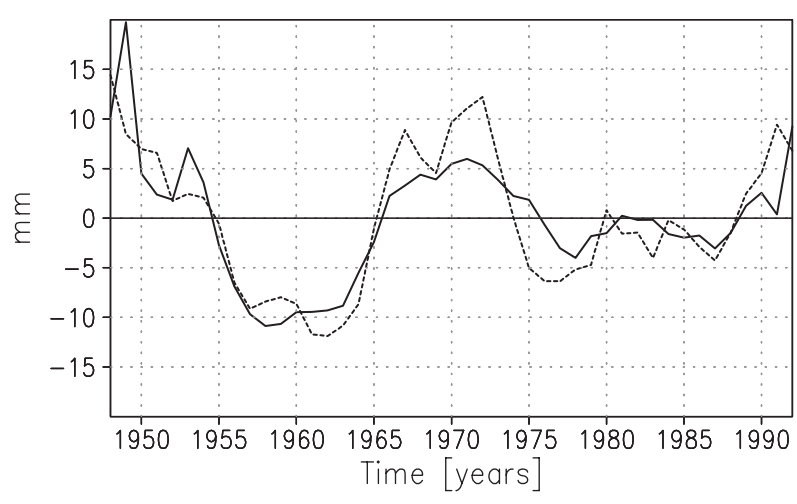

Fig. 10. Annual accumulation anomalies at B21. Solid line: full model (cross-validated) (see text), dashed line: observed ice core

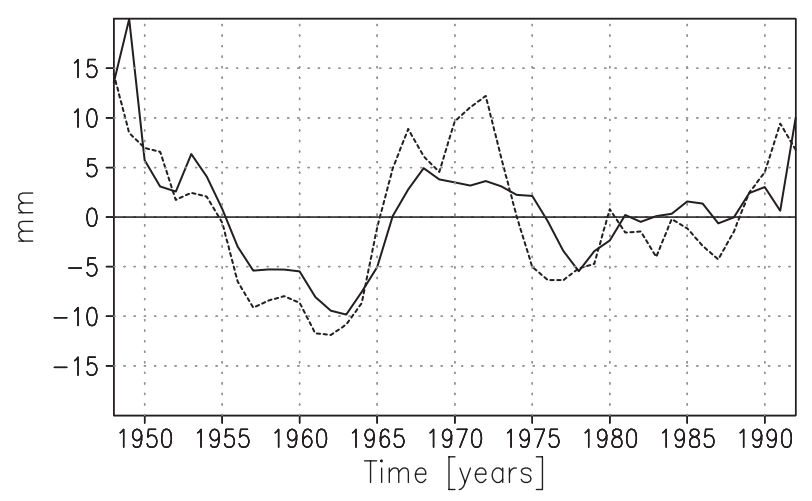

Fig. 11. Annual accumulation anomalies at B21. Solid line: stream-function model (cross-validated) (see text), dashed line: observed ice core

EOF pattern shows small negative anomalies for the whole area, with a minimum in central Greenland, indicating that positive annual ice accumulation anomalies at B21 are related to negative annual temperature anomalies over Greenland (Fig. 12). In contrast to the stream-function field discussed above, the $700 \mathrm{hPa}$ temperature field has only 1 PC noticeably correlated with B21 accumulation. Thus only about half of the ice accumulation variability can be explained by temperature, whereas the summer-mean stream-function field explains about two-thirds of the variance. In comparison to the validated stream-function derived ice accumulation (Fig. 11), the validated temperature derived ice accumulation (Fig. 13) does not reproduce the general behavior of the observed ice accumulation. Only the minimum in 1957 and the maximum in 1971-72 are better reproduced than by the stream-function model.

As mentioned earlier, the correlation between the NAO index and B21 accumulation from 1825 to 1993 is negligible. To confirm this result for the regression model, we correlated the NAO index with the PCs 


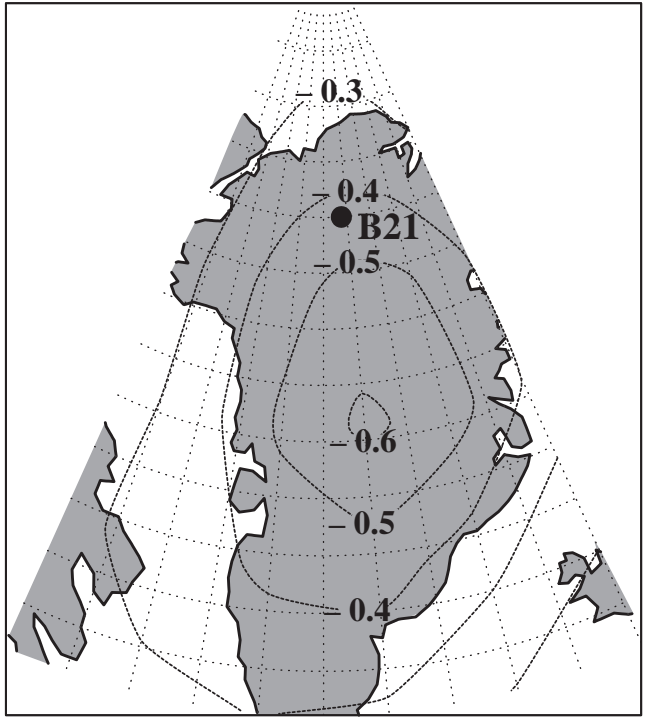

Fig. 12. First EOF pattern of the annual mean NCEP temperature field $(700 \mathrm{hPa})$

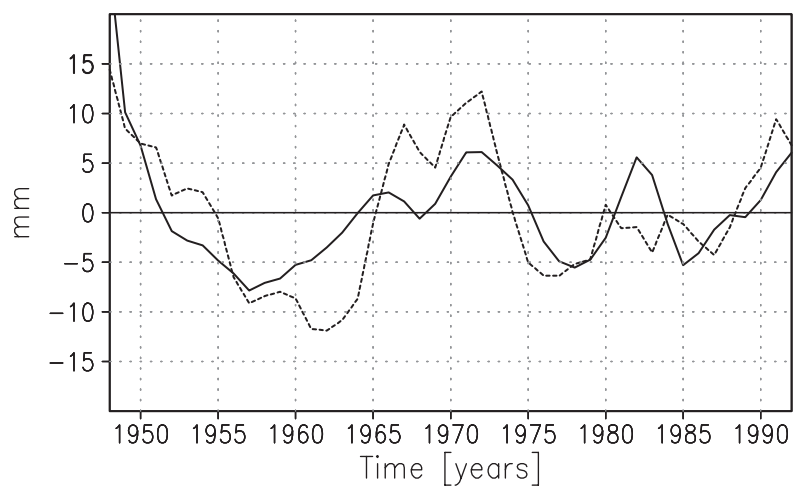

Fig. 13. Annual accumulation anomalies at B21. Solid line: temperature model (cross-validated) (see text), dashed line: observed ice core

representing the regression model. The correlation between the PCs of the $500 \mathrm{hPa}$ stream-function field (mean field from May to August) and the annual NAO index yields only for the 2nd PC a weakly significant correlation of 0.25 . Since we did not smooth the data, this is only just statistically significant (at the $95 \%$ level). However, this PC is not used in the regression model. The coefficients for the other PCs are not significant. For the temperature PCs used in the regression model, we found that the 3rd and the 4th PCs are almost uncorrelated with the NAO index. Only the 1st and the 2nd PCs, which are not used in the regression model, have significant correlation coefficients of 0.48 and 0.31 respectively. Thus the regression model for B21 only incorporates PCs which are uncorrelated with the NAO index.

\section{DISCUSSION AND CONCLUSIONS}

We have shown that it is possible to construct a plausible statistical relationship between large-scale atmospheric data and local ice accumulation. Keeping in mind that there are several error sources and uncertainties which affect the ice core data, the explained variance of $71.5 \%$ (using cross-validation) is very high.

The time series of annual accumulation rates of B21 essentially represents the summer circulation over the Greenland, North Atlantic and north European region. Nearly two-thirds of the total variance of local ice accumulation is described by EOF patterns of this streamfunction field, which represents about $80 \%$ of streamfunction variability. Thus we can confirm the results from Ohmura \& Reeh (1991), Chen et al. (1997) and Serreze et al. (1993) that mainly the summer months contribute to the annual precipitation totals in north Greenland. The EOF patterns have structures which can plausibly be related to precipitation anomalies. The first, which accounts for the greatest amount of variability of ice accumulation shows weakly cyclonic circulation in the polar region, which leads to westerly winds near the site of B21. This may be related to the weak cyclonic activity in summer found by Serreze et al. (1993), which is assumed to account for precipitation in this area. The 3rd and the 4 th stream-function patterns relate northerly winds to the site of B21 when accumulation is high. All 3 patterns correspond with the results obtained from the correlation map between NCEP precipitation and B21 ice accumulation (Fig. 2). The highest positive correlation coefficients were found north and northwest of the core site. It also confirms the results obtained by Ohmura \& Reeh (1991) and by Chen et al. (1997), who found that precipitation in north Greenland is caused by lows over the polar region (Ohmura \& Reeh 1991) or near the northwest or northeast coast of Greenland (Chen et al. 1997) during summer months. In addition to the dominant streamfunction proportion, temperature yields only a small contribution to ice accumulation variability for B21. The 3rd and the 4th PCs of annual mean temperature $(700 \mathrm{hPa})$, representing the area of east Canada to east Greenland, make a contribution to the explained variance of $7.5 \%$.

Besides the regression model based on the summer-mean stream-function field, we found a statistically significant correlation between B21 accumulation time series and the 1st PC of $700 \mathrm{hPa}$ temperature derived from the annual mean field over Greenland. The temperature pattern describes about half of the local ice accumulation variability. It relates positive ice accumulation anomalies to negative temperature anomalies over the entire Greenland area. 
This contradicts a commonly used relationship, that ice accumulation is positively correlated with nearsurface local annual mean temperature. However, one should keep in mind that the $700 \mathrm{hPa}$ temperature roughly represents the $3000 \mathrm{~m}$ height, but not the near-surface level for the site of B21 $(2145 \mathrm{~m})$. On the other hand, the commonly used relationship between precipitation and near-surface annual temperature depends on the assumption that there is only a weak seasonality of precipitation, which is obviously not fulfilled for the site of B21. Thus the negative correlation between annual $700 \mathrm{hPa}$ temperature and B21 accumulation should not be extrapolated to other Greenland sites, especially sites in the southern or coastal regions, since here the seasonality of precipitation is different (Putnins 1970, Ohmura \& Reeh 1991).

We have shown that the PCs of the regression model have sufficiently high correlation coefficients to describe $71.5 \%$ of B21 accumulation variability. However, the correlations between the PCs of the regression model and NCEP precipitation around B21 are negligible. This confirms the above-mentioned argument that more reliably simulated fields such as largescale velocity or temperature fields should be used as predictors.

Since we have found a regression model which describes $71.5 \%$ of local ice accumulation variability, it would be reasonable to apply this regression model to GCM data. Thus 'artificial ice accumulation' could be derived for climate-change simulations performed, for example, with a doubled $\mathrm{CO}_{2}$ concentration. On the other hand, ice accumulation estimated from paleoclimate simulations provides the possibility of validating these estimates against long-time-scale ice cores. This would also permit validation of the GCMs with regard to the reproduction of past climate states. We believe that the method presented here of developing an empirical relationship between large-scale atmospheric data and local ice accumulation is applicable to other cores as well, which offers the possibility for broad investigations of GCM-derived ice accumulation. However, in spite of the encouraging results obtained for the ice core examined here, it should be noted that the empirically derived relationship is based on a short period of only 45 yr. Processes which did not occur during the fitting period or fundamental changes of circulation are not described by the statistical model. Thus these effects cannot be explored using GCM data. Especially when the regression model is applied to GCM data which describe future or past climate states, it should be kept in mind that both the regression model and the GCM are developed under present-day climate conditions.
Acknowledgements. This work was financed by the 'Frauenförderung' of the University of Hamburg. It was performed in co-operation with the HGF project 'Climate in Historical Times'. We thank the AWI Bremerhaven for providing the ice core data, and especially Matthias Schwager for helpful discussions. We also thank Ute Luksch from the University of Hamburg and Eduardo Zorita from GKSS Research Centre for their support and helpful ideas.

\section{LITERATURE CITED}

Appenzeller C, Schwander J, Sommer S, Stocker TF (1998a) The North Atlantic Oscillation and its imprint on precipitation and ice accumulation in Greenland. Geophys Res Lett 25(11):1939-1949

Appenzeller C, Stocker TF, Anklin M (1998b) North Atlantic oscillation dynamics recorded in greenland ice cores. Science 282:446-449

Barlow LK, Rogers JC, Serreze MC, Barry RG (1997) Aspects of climate variability in the North Atlantic sector : discussion and relation to the Greenland Ice Sheet Project 2 high-resolution isotopic signal. J Geophys Res 102: 26333-26344

Chen QS, Bromwich DH, Bai L (1997) Precipitation over Greenland retrieved by a dynamic method and its relation to cyclonic activity. J Clim 10(5):839-870

Dahl-Jensen D, Johnsen SJ, Hammer CU, Clausen HB, Jouzel J (1993) Past accumulation rates derived from observed annual layers in the GRIP ice core from Summit, Central Greenland. In: Peltier WR (ed) NATO ASI Series I12: Ice in the climate system. Springer-Verlag, Berlin

Fischer H (1997) Räumliche Variabilität in Eiskernzeitreihen Nordgrönlands. Dissertation, Universität Heidelberg

Fischer H, Wagenbach D, Kipfstuhl J (1998a) Sulfate and nitrate firn concentrations on the Greenland ice sheet 1. Large-scale geographical deposition changes. J Geophys Res 103(D17):21927-21934

Fischer H, Wagenbach D, Kipfstuhl J (1998b) Sulfate and nitrate firn concentrations on the Greenland ice sheet 2. Temporal anthropogenic deposition changes. J Geophys Res 103(D17):21935-21942

Heidam NZ (1984) The components of the arctic aerosol. Atmos Environ 18(2):329-343

Johnsen SJ, Dahl-Jensen D, Dansgaard W, Gundestrup N (1995) Greenland palaeotemperatures derived from GRIP bore hole temperature and ice core isotope profiles. Tellus 47B(5):624-629

Jones PD, Jonsson T, Wheeler D (1997) Extension to the North Atlantic Oscillation using early instrumental pressure observations from Gibraltar and South-West Iceland. Int J Clim 17 1433-1450

Jouzel J, Alley RB, Cuffey KM, Dansgaard W and 9 others (1997) Validity of the temperature reconstruction from water isotopes in ice cores. J Geophys Res 102: 26471-26487

Kalnay E, Kanamitsu M, Kistler R, Collins W and 18 others (1996) The NCEP/NCAR 40-year reanalysis project. Bull Am Meteorol Soc 77(3):437-471

Leung LR, Ghan SJ (1998) Parameterizing subgrid orographic precipitation and surface cover in climate models. Mon Weather Rev 126:3271-3291

Ohmura A, Reeh N (1991) New precipitation and accumulation maps for Greenland. J Glaciol 37(125):140-148

Putnins P (1970) The climate of Greenland. In: Orvig S (ed) Climates of the polar regions, Vol 14. Elsevier, New York, p 3-128 
Rogers JC, Bolzan JF, Pohjola VA (1998) Atmospheric circulation variability associated with shallow-core seasonal isotopic extremes near Summit, Greenland. J Geophys Res 103(D10):11205-11219

Schwager M (2000) Eisbohrkernuntersuchungen zur räumlichen und zeitlichen Variabilität von Temperatur und Niederschlagsrate im Spätholozän in Nordgrönland. Reports on Polar Research 362, Alfred Wegener Institute for Polar and Marine Research, Bremerhaven

Serreze MC, Box JE, Barry RG, Walsh JE (1993) Characteristics of arctic synoptic activity, 1952-1989. Meteorol Atmos Phys 51:147-164

Stendel M, Arpe K (1997) Evaluation of the hydrological cycle in reanalysis and observations. Report No. 228, Max Planck Institute of Meteorology, Hamburg

von Storch H, Zwiers FW (1999) Statistical analysis in climate research. Cambridge University Press, Cambridge

von Storch H, Zorita E, Cubasch U (1993) Downscaling of global climate change estimates to regional scales: an application

Editorial responsibility: Clare Goodess,

Norwich, United Kingdom to Iberian rainfall in wintertime. J Clim 6:1161-1171

Washington WM Parkinson CL (1986) An introduction to three-dimensional climate modeling. Oxford University Press, Oxford

White JWC, Gorodetzky D, Cook ER, Barlow LK (1996) Frequency analysis of an annually resolved, 700 year paleoclimate record from the GISP2 ice core. In: Jones PD, Bradley RS (eds) NATO ASI Series I41: Climatic variances and forcing mechanisms of the last 2000 years. SpringerVerlag, Berlin

White JWC, Barlow LK, Fisher D, Grootes P, Jouzel J, Johnsen SJ, Stuiver M, Clausen H (1997) The climate signal in the stable isotopes of snow from Summit, Greenland: results of comparisons with modern climate observations. J Geophys Res 102:26425-26439

Widmann M, Bretherton CS (2000) Validation of mesoscale precipitation in the NCEP reanalysis using a new grid-cell dataset for the Northwestern United States. J Clim 13: 1936-1950

Submitted: January 31, 2000; Accepted: July 12, 2001

Proofs received from author(s): January 3, 2002 